\title{
Impact Assessment of KVK Training Programme in Nagaon district of Assam, India
}

\author{
Sinki Barman ${ }^{1 *}$, Niranjan Deka ${ }^{2}$ and Pallavi Deka ${ }^{3}$ \\ ${ }^{1}$ Krishi Vigyan Kendra, Simoluguri, Nagaon, Assam, India \\ ${ }^{2}$ Krishi Vigyan Kendra, Udalguri, India \\ ${ }^{3}$ Assam Agricultural University, Jorhat, India \\ *Corresponding author
}

\section{Keywords \\ Scientific \\ Orientation, Impact, \\ Adoption behavior, \\ Farming}

\section{Article Info}

Accepted:

10 July 2020

Available Online:

10 August 2020

\section{A B S T R A C T}

The present study was undertaken in Nagaon district of Assam, India. Imparting training is also a main purpose of KVK. But there a few studies have been done in the impact of KVK training on adoption behavior of the beneficiaries. Therefore, in the present study an attempt has been made to examine the impact of KVK training on adoption behavior of respondents a study entitled "Impact Assessment of KVK training programme in Nagaon district of Assam, India" has been conducted.200 farmers were selected to examine the impact of KVK training programme. This study was undertaken to assess attitude and to explore the relationship between attitude and profile of the farmers towards KVK training programmes . With the help of pretested interview schedule all data collected from respondents pertains to the year 2018-19. Tabular, percent analyses with proper analytical tools were used to access the above study. Apart from these, Logit Regression Analysis was done for various respondents in order to study factor affecting the impact of training. Majority of the respondents (63\%) have land holding of size below 1 ha and 99 per cent of the respondents have farming experience of more than 20 years reveals that training received at KVK had shown positive significant at 5 per cent probability level with impact of training and scientific orientation was positively and significantly related with impact of training.

\section{Introduction}

Famous English economist and demographer, Malthus documented in his book namely "Essay on the Principle of Population" published in 1798 that human populations grow exponentially whereas the food production grows at an arithmetic rate. Therefore, increasing in supply of food production has a great importance for food demand for growing population as well as economic growth of a country. Establishment of Krishi Vigyan Kendras (KVKs) are utmost necessary for transfer of new technologies to the rural farmers in order to meet the above objectives. There are 716 nos. of KVKs established throughout India. Fischer (2015) stated that Impact Assessment provide for an overview of achievements, gaps and future directions for policy.[1] Imparting training is 
also a main purpose of KVK.Amhed et al., (2012)examined the Farmers' Assessment of KVK Training Programme at Uttar Pradesh and Uttranchal and found that 52.29 per cent of the respondents have realized increase in productivity of enterprise [2]. But there a few studies have been done in the impact of KVK training on adoption behavior of the beneficiaries. Therefore, In the present study an attempt has been made to examine the impact of KVK training on adoption behavior of respondents a study entitled "Impact Assessment of KVK training programme in Nagaon district of Assam, India" has been conducted.

\section{Materials and Methods}

The study was conducted in Nagaon district of Assam, India. The sampling design followed for the study was stratified random sampling. Five villages were selected where trainings were given on agricultural aspects like crop production, soil management, livestock management, fishery management, marketing and other enterprise. 40 numbers of respondents were randomly selected from each of the villages, thus 200 farmers were selected to examine the impact of $\mathrm{KVK}$ training programme. This study was undertaken to assess attitude and to explore the relationship between attitude and profile of the farmers towards KVK training programmes. With the help of pretested interview schedule all data collected from respondents pertains to the year 2018-19. Tabular, percent analysis with proper analytical tools were used to access the above study. Apart from these, Logit Regression Analysis was done for various respondents in order to study factor affecting the impact of training. Farmers' responses of each parameter are codified as scores. Sing et al., (2010) also used Logit model to analyze the factor affecting of training adoption [3]. Barman et al., (2019) also used Logit
Regression analysis to examine the factors affecting farm mechanization [4]. Logit Analysis was with the help of following formula:

$$
\mathrm{P}=1 /\left(1+\mathrm{e}^{-\mathrm{AL}}\right)
$$

Where, $\mathrm{P}$ is the probability that famers adoption level

$$
\begin{aligned}
& \mathrm{AL}=\mathrm{x}_{(1)}+\mathrm{x}_{(2)}{ }^{*} \mathrm{AGE}+\mathrm{x}_{(3)}{ }^{*} \mathrm{OCC}+\mathrm{x}_{(4)}{ }^{*} \\
& \mathrm{EDU}+\mathrm{x}_{(5)} * \mathrm{LH}+\mathrm{x}_{(6)} * \mathrm{TRN}+\mathrm{x}_{(7)} * \mathrm{SO}+\mathrm{x}^{*} \\
& { }_{(8)}^{*} \mathrm{EF}+\mathrm{x}(9) * \mathrm{IO}
\end{aligned}
$$

Where,

a) AGE is the age of head of the household (proxy for experience)

b) OCC is the Occupation of the farmers, farming: 1 otherwise 0

c) EDU is the maximum education level of the household

d) LH is the farm size

e) TRN is the Training received at KVK

f) $\mathrm{SO}$ is Scientific orientation $\mathrm{YES}=1,0$ Otherwise

g) $\mathrm{EF}$ is the Experience in Farming.

h) IO is the Innovative proneness

i) AL is Adoption Level

\section{Results and Discussion}

In his chapter there is an attempt to investigate the profile of the farmers resulting their attitude on training and categorization according to their adoption level and analyses different factors affecting the impact of training with brief description. Katole et al., 
(2017) also conducted study on impact analysis of KVK trainings and its affect on farmers attitude and relationship with profile of farmers with their attitude towards training [5]. Table 1 reveals that majority of the respondents are under the age of below 35 . This findings is in conformity with the findings of Nazir et al., 92012) that majority of the trainees $(77.75 \%)$ belonged to the age group of 15- 25 years. To examine Impact of Vocational Training Courses in Kashmir [6]. Most of the respondents have education up to IV standard (98\%). 93 per cent of the total respondents practice faming and animal husbandry as a source of income. Majority of the respondents (63\%) have land holding of size below 1 ha and 99 per cent of the respondents have farming experience of more than 20 years. This is in consistency with the finding by Barman and Deka (2019) that very few farmers were found to have land holding more than 3 hectares in Assam [7]. Majority of respondents opined that percentage of Training received at $\mathrm{KVK}$ was medium at 81.33. Similarly regarding the content of the training Programme based on scientific orientation. 42 per cent of the respondent had high level of adoption followed by medium level of adoption which was 40.50 per cent. The per cent of lowest level of adoption was 17.50

Table.1 Profile of The famers

\begin{tabular}{|c|c|c|}
\hline $\begin{array}{l}\text { Sl. } \\
\text { No. }\end{array}$ & Category & Percent (\%) \\
\hline \multirow[t]{4}{*}{1} & \multicolumn{2}{|l|}{ Age } \\
\hline & Young (up to 35 years) & 64 \\
\hline & Middle Age ( 36 to 50 years) & 59 \\
\hline & Old Age ( above 50 years) & 27 \\
\hline \multirow[t]{6}{*}{2} & \multicolumn{2}{|l|}{ Education } \\
\hline & Illiterate & 5 \\
\hline & Primary (up to IV std.) & 98 \\
\hline & Secondary school (V to X std.) & 28 \\
\hline & Higher Secondary ( XI to XII) & 13 \\
\hline & Graduation \& above & 6 \\
\hline \multirow[t]{4}{*}{3} & \multicolumn{2}{|l|}{ Occupation } \\
\hline & Farming & 51 \\
\hline & Farming + Animal Husbandry & 93 \\
\hline & Farming + Animal Husbandry+ Service & 6 \\
\hline \multirow[t]{4}{*}{4} & \multicolumn{2}{|l|}{ Size of holding } \\
\hline & Marginal ( up to 1ha) & 63 \\
\hline & Small ( 1 to 2 ha) & 58 \\
\hline & Medium and above (more than $2 \mathrm{ha}$ ) & 29 \\
\hline \multirow[t]{5}{*}{5} & \multicolumn{2}{|l|}{ Experience in Farming } \\
\hline & $<5$ years & 0 \\
\hline & 5 to 10 years & 15 \\
\hline & $11-20$ years & 36 \\
\hline & More than 20 years & 99 \\
\hline
\end{tabular}


Table.2 Effect of Training at KVK on farmer's attitude

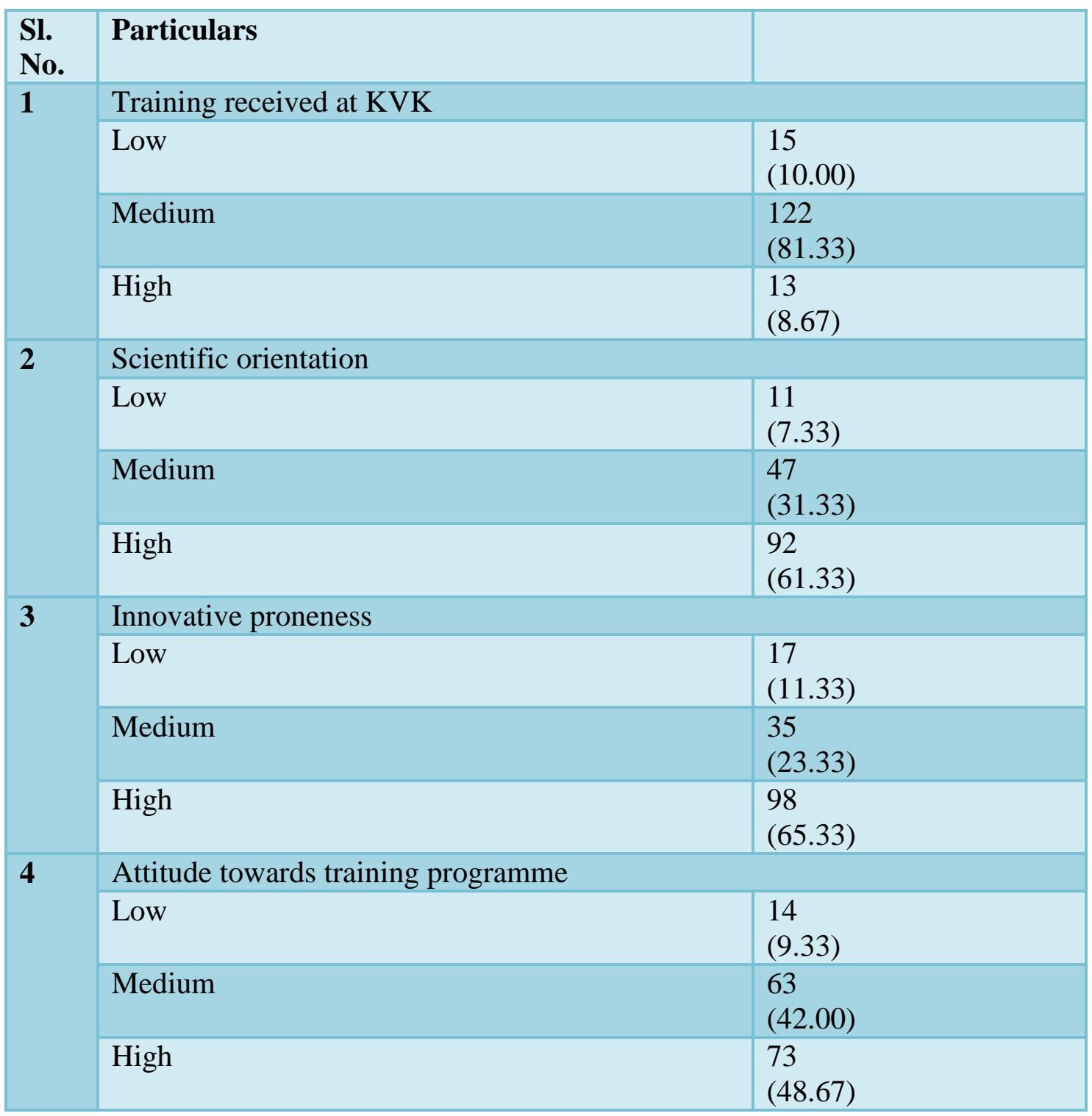

*Figure in parentheses indicates percentage of the total

Table.3 Distribution of respondents according to the level of adoption

\begin{tabular}{|l|c|c|}
\hline Level & Frequency & Percentage \\
\hline Lowest level & 35 & 17.50 \\
\hline Medium level & 81 & 40.50 \\
\hline High level & 84 & 42.00 \\
\hline Total & 200 & 100.00 \\
\hline
\end{tabular}


Table.4 Co relation Coefficient of trainees according to independent variable

\begin{tabular}{|l|l|l|}
\hline $\begin{array}{l}\text { Sl } \\
\text { No. }\end{array}$ & Independent Variables & Correlation Coefficient \\
\hline $\mathbf{1}$ & Age & 1.4523 \\
\hline $\mathbf{2}$ & Occupation & -0.04126 \\
\hline $\mathbf{3}$ & Education & $-2.1345^{*}$ \\
\hline $\mathbf{4}$ & Size of holding & 0.09657 \\
\hline $\mathbf{5}$ & Training received at KVK & $1.9961^{*}$ \\
\hline $\mathbf{6}$ & Scientific orientation & $2.6748^{* *}$ \\
\hline $\mathbf{7}$ & Experience in Farming & 1.6587 \\
\hline $\mathbf{8}$ & Innovative proneness & 1.8561 \\
\hline *Significant at 5\% probability level & \\
\hline ** Significant at 1 \% probability level & \\
\hline
\end{tabular}

Data presented in Table 2 shows the famers attitude towards training Programme. Majority of respondents opined that percentage of Training received at KVK was medium at 81.33. Similarly regarding the content of the training Programme based on Scientific orientation, majority felt high at 61.33 per cent. Only few respondents $(7.33 \%)$ felt that content was not scientifically orientate. Majority (65.33\%) found the training programmes as innovative proneness whereas a few (11.33\%) found it as less innovative proneness. 48.67 per cent had high response towards attitude of the training programmes. Jamir and Sharma (2018) reported that training for the farmers should be based on effective control of insect, pest and diseases in order to uplift rural community [8].

Table 3 reveals the different level of adoption amongst respondents. It shows that 42 per cent of the respondent had high level of adoption followed by medium level of adoption which was 40.50 per cent. The per cent of lowest level of adoption was 17.50. Christopher et al., (2018) was also found in their study on adoption behavior of maize growers in Bihar that lowest level of adoption was 16.25 per cent respondents in trainees categories [9].
Table 4 reveals that training received at KVK had shown positive significant at 5 per cent probability level with impact of training and scientific orientation was positively and significantly related with impact of training. Both Occupation and Education had negatively related with impact of training where occupation was insignificant with impact of training. The others variable viz., Ager, Size of holding, Experience in Farming, Innovative proneness had positive insignificant relationship with impact of training. Ayandiji and Olofinsao (2015) also studied the socio economic factors affecting farm mechanization by cassava farmers in Ondo State, Nigeria and logistic regression analysis model to examine the factors and found that access to extension workers and access to farm machines had a positive relationship with adoption [10].

\section{References}

Ahmad, Nafees.; Singh, S.P., Parihar,P.(2012) Farmers' Assessment of KVK Training Programme. Indian Research Journal of Extension Education Special Issue (Volume I), January, 2012

Ayandiji, A. and Olofinsao, O.T. (2014). Socio Economic Factors affecting Adoption of Farm Mechanization by 
Cassava Farmers in Ondo State, Nigeria. IOSR Journal of Environmental Science, Toxicology and Food Technology 9(3): $39-45$

Barman, Sinki., Deka, N. (2019)Status of Farm Mechanization in Assam. Research Journal of Agricultural Sciences. 10(2): 358-362

Barman, Sinki., Deka, N., Deka. P. (2019) Factors Affecting Farm Mechanization A Case Study in Assam, India. Asian Journal of Agricultural Extension, Economics \& Sociology 32(1): 1-7, 2019; Article no.AJAEES.48079

Christopher, K.; Srivastava, J.P. ,Jahanara(2018).Impact of Krishi Vigyan Kendra (KVK) training program on adoption behaviour of maize growers in Bettiah block of west Champaran district of, (Bihar).Journal of Pharmacognosy and Phytochemistry 2018; 7(3): 1843-1844

Fischer, B.T.; Impact Assessment Research achievements, gaps and future directions. Journal of Environmental Assessment Policy Management.Vol.17, No.1 (March, 2015)1501001 (12 pages)
Jamir, Imsunaro.; Sharma, A.(2018)Impact Assessment on Income and Employment of Krishi Vigyan Kendra Training Programmes in Nagaland. International Journal of Current Microbiology and Applied Sciences. (2018) 7(11): 18921901

Katole, S.B., Bhatt, J. H., Patel, G.G. (2017).Impact Analysis Of Activities Of Krishi Vigyan Kendra.Gujrat Journal of Extension Education. Vol. 28: Issue 2 : December 2017.

Nazir, Tabasum., Vaida1, N., Ahmad, M. D.(2011).The Impact of Vocational Training Courses on Knowledge and Adoption of Rural Women in Kashmir. Journal of Sustainable Society (2012).Vol. 1, No. 4, 2012, 84- 87.

Singh, K.; Peshin, R., Saini, S. K.(2010)Evaluation of the agricultural vocational training programmes conducted by the Krishi Vigyan Kendras (Farm Science Centres) in Indian Punjab. Journal of Agriculture and Rural Development in the Tropics and Subtropics.Vol. 111 No. 2 (2010) 65-77.

\section{How to cite this article:}

Sinki Barman, NiranjanDeka and Pallavi Deka. 2020. Impact Assessment of KVK Training Programme in Nagaon district of Assam, India. Int.J.Curr.Microbiol.App.Sci. 9(08): 996-1001. doi: https://doi.org/10.20546/ijcmas.2020.908.108 